\title{
Uso de água subterrânea em sistema de abastecimento público de comunidades na várzea da Amazônia central ${ }^{1}$
}

\begin{abstract}
Rainier Pedraça de AZEVEDO²
RESUMO

O paradoxo das águas marca as populações amazônicas que habitam as várzeas. Se na cheia as águas abundam, na seca escasseiam, chegando desfalcar os ribeirinhos seja pela insuficiência e/ou por condições impróprias para consumo. Esse trabalho descreve o aproveitamento do manancial subterrâneo para abastecimento público, através de poço tubular construído na comunidade de várzea de Santo Antônio, no município de Urucará, Estado do Amazonas. O estudo demonstrou a ocorrência de variações nas características físico-químicas da água do poço durante um ciclo das de superfície da região, principalmente a elevação do teor de ferro total no período de cheia máxima, sendo esse um indicativo de falha no processo construtivo do poço, uma vez que a água subterrânea local apresenta condições satisfatórias para o consumo humano. $\mathrm{O}$ aproveitamento do manancial subterrâneo em sistemas de abastecimento de água em comunidades de várzea na Amazônia é tecnicamente viável, entretanto, carece de obras de captação corretas, visando a conservação da qualidade da água desse rico ecossistema.
\end{abstract}

\section{PALAVRAS-CHAVE}

Água subterrânea, sistema de abastecimento de água, várzeas da Amazônia

\section{The use of groundwater in public water supply system of floodplain communities in the central Amazonia}

\begin{abstract}
The Amazonian populations that live in the floodplains are marked by a water paradox. If in the flood season water is plentiful, during the drought period water is scarce, either not having enough for the people's needs or it is inappropriate for human consumption. This paper describes the use of groundwater for public water supply system through a tubular well built in Santo Antonio floodplain community, in the district of Urucara, Amazonas State. The study has shown the occurrence of variations in the water quality of the well during the cycle of the superficial water, mainly an increase in the level of iron. This indicates a fault in the building process of the well, given that the local groundwater has good quality for consumption. The use of groundwater in public supply system in the floodplain communities in the Amazon is technically feasible. However it needs proper well construction techniques in order to preserve the quality of the groundwater of that rich ecosystem.
\end{abstract}

\section{KEY-WORDS}

Groundwater, water supply system, Amazon floodplains

${ }^{1} 0$ artigo baseia-se em parte da dissertação de mestrado do autor.

${ }_{2}^{2}$ FUNASA - Fundação Nacional de Saúde/AM, Rua Oswaldo Cruz S/N, Glória, Manaus-AM, 69.027-000, Tel: (92) 3672-1134, Fax: (92) 3672-1132, e-mail: rainier.pedraca@saude.gov.br 


\section{INTRODUÇÃO}

As várzeas são áreas úmidas (florestas e campos) periodicamente inundadas, que ocorrem principalmente na calha do rio Solimões-Amazonas (3.500 km de extensão). As larguras das várzeas variam de algumas centenas de metros em trechos do Alto Solimões, passando por larguras médias de $50 \mathrm{~km}$ ao longo do Médio e Baixo Amazonas até $200 \mathrm{~km}$ na foz do Amazonas (Diegues, 2002).

As populações amazônicas que habitam as várzeas, invariavelmente, fixam-se às margens dos cursos de águas. $\mathrm{Na}$ várzea, a vida se move com ciclo das águas, que sobem e descem, inundam e secam, abundam e escasseiam, chegando a ter variaçōes entre os picos de cheia e seca superiores a dez metros. $\mathrm{Na}$ vazante dos rios, muitos mananciais superficiais secam completamente ou ficam com pouca lâmina de água, inviabilizando sua utilização, seja pela insuficiência, e/ou por condiçōes impróprias para consumo humano.

A classificação das águas superficiais da Amazônia feita por Sioli (1950) apud Martinelli (1986), baseia-se principalmente nas características ópticas, associadas às características químicas dos rios e sua área predominante de ocorrência, assim descrita: rios de águas brancas (ex: rio Amazonas), rios de águas pretas (ex: rio Negro) e rios de águas claras com exemplo do rio Tapajós. Segundo Junk (1983), os rios de várzea são na sua maioria de águas brancas, pois são ricos em material particulado em suspensão de origem andina, o que confere a essas águas uma alta turbidez e um $\mathrm{pH}$ aproximando-se do neutro variando de 6,2 a 7,2.

As águas superficiais raramente estão livres de contaminação, mesmo nas bacias de mananciais com pouca ou nenhuma presença humana. Segundo Urban (1999), a ocupação desordenada de uma bacia provoca grandes alteraçôes na qualidade da água gerada por atividades humanas (produção de esgotos) e impurezas trazidas pelo escoamento das águas das chuvas, ou atividades rurais, como a presença de agrotóxicos, de grande volume de sedimentos erodidos ou de dejetos de animais.

Dependendo do grau de conservação, as águas superficiais na várzea, no geral, são de fácil tratamento. $\mathrm{O}$ pH, a turbidez entre outros parâmetros, facilitam o processo de tratamento, contudo, esse processo requer a utilização de equipamentos mecânicos, aplicação de produtos químicos para adequação da água aos padrões de potabilidade exigidos pela legislação, além de necessitar de pessoal treinado para operar e manter continuamente o sistema, o que nem sempre é possível nas comunidades isoladas, dispersas e ainda sujeitas a inundação periódicas na Amazônia.

Uma solução possível é o aproveitamento do manancial subterrâneo, através de poço tubular. Azevedo Netto \& Alvarez (1991) recomendam a perfuração de poços tubulares profundos desde que seja comprovado o potencial da camada aqüífera no local da perfuração ou nas suas imediaçōes e desde que esse potencial atenda à demanda de água prevista para a comunidade a ser atendida.

$\mathrm{Na}$ Amazônia, é crescente a perspectiva de explotação da água subterrânea, por apresentar vantagens práticas e econômicas quanto à sua captação, por dispensar tratamentos químicos exceto desinfecção - e ser de excelente qualidade, além de abundante, justificando sua utilização. No entanto, Azevedo (2004) afirma que na várzea Amazônica pouco se investe em pesquisas destinadas ao aproveitamento das águas subterrâneas para o consumo humano, com isso tem aumentado o insucesso de vários sistemas que utilizam esse manancial como fonte de suprimento, seja pela má qualidade das águas dos lençóis captados ou por técnicas inadequadas de construção de poços.

O objetivo do trabalho foi descrever o aproveitamento do manancial subterrâneo para abastecimento público de água, através de poço tubular construído em uma área de várzea na Amazônia Central (comunidade de Santo Antônio, no município de Urucará - AM). Foi dada ênfase na observação da variação das características físico-químicas da água subterrânea durante um ciclo das águas superficiais, verificando a influência dessas águas na alteração da qualidade da água subterrânea explotada pelo poço tubular.

\section{MATERIAL E MÉTODOS}

\section{ÁREA DE ESTUDO}

O estudo foi realizado na comunidade de várzea de Santo Antônio, na localidade do Paraná do Comprido, ligada administrativamente ao município de Urucará, Estado do Amazonas. Geograficamente essa região está compreendida entre os paralelos $2^{\circ} 25^{\prime} \mathrm{S}$ e $2^{\circ} 30^{\prime} \mathrm{S}$ e os meridianos de $57^{\circ} 25^{\prime} \mathrm{W}$ e $57^{\circ} 35^{\prime} \mathrm{W}$, conforme mostra a figura 1 .

Essa comunidade situa-se a margem direita do rio Amazonas e dista $25 \mathrm{~km}$ em linha reta da sede municipal e aproximadamente $35 \mathrm{~km}$ por via fluvial (na seca dos rios). Em relação a cidade de Manaus, capital do Estado do Amazonas, dista $290 \mathrm{~km}$ em linha reta e aproximadamente $340 \mathrm{~km}$ por via fluvial. É abrangida por uma extensa faixa de várzea com largura que pode chegar a 50 $\mathrm{km}$, só perdendo em largura para o estuário do rio Amazonas.

Geologicamente a área de estudo situa-se no centro da Bacia Sedimentar do Amazonas e, apresenta as maiores possibilidades aquíferas em função da Formação Alter do Chão de idade cretácea. Essa formação é constituída por argilas, siltes e areias interdigitadas, predominantemente vermelhas, mal selecionadas, feldspáticas e com conteúdo variável de micas, distribuindo-se por toda a Amazônia Ocidental (Petri \& Fúlfaro,1983), é sobreposta por sedimentos aluviais dos rios da região, pertencentes ao Quaternário e constituídos de seixos, areias, siltes e argilas, com destaque para os sedimentos aluviais da planície de inundação do rio Amazonas, estes com predominância argilosa e de coloração cinza 


\section{ACTA}

A escolha dessa comunidade para o estudo de caso foi motivada por se tratar de um dos primeiros sistemas de abastecimento de água projetado e construído em área rural de várzea na Amazônia, com utilização de água subterrânea e por abastecer diversas comunidades com um único poço tubular.

\section{COLETA E TRATAMENTO DE DADOS}

No período de desenvolvimento do trabalho de campo, foram realizadas três visitas, em períodos distintos, contemplando o regime de pulso das águas. A primeira iniciou nos primeiros dias do mês de fevereiro de 2003, onde as águas estavam em ascensão, já a segunda, ocorreu no final do mês de junho de 2003, época de cheias máximas e a última visita se deu em meados do mês de novembro de 2003, quando nessa época, o local encontrava-se seco e as águas se preparavam para subir novamente e iniciar mais um ciclo.

Foram realizados registros fotográficos, determinações de altitudes e coordenadas geográficas, coletas de água do manancial subterrâneo e de superfície.

As coletas de água foram realizadas no manancial de superfície (rio Amazonas) e no manancial subterrâneo (poço tubular da comunidade de Santo Antônio), em diferentes épocas do ciclo das águas superficiais. Procurou-se coletar as amostras sempre nos mesmos pontos de referência e, de cada local coletou-se uma amostra. Para água de superfície a coleta foi realizada aproximadamente a cinco metros da margem do rio (local onde geralmente se instalam as captações flutuantes) a $30 \mathrm{~cm}$ de profundidade, já a coleta da água do poço foi realizada diretamente do barrilete após um funcionamento mínimo de 15 minutos do poço.

As amostras para análises físico-químicas da água foram coletadas, preservadas e transportadas segundo as recomendaçōes do Guia de Coleta de Amostras de Água, publicado pela Companhia de Tecnologia de Saneamento Ambiental - CETESB (1987), até o Laboratório de Controle da Qualidade da Água - LCQA da Fundação Nacional de Saúde - FUNASA em Manaus - AM, onde foram examinadas.

As variáveis físico-químicas analisadas foram: $\mathrm{pH}$ e condutividade por potenciometria; dureza total por titulometria; cor aparente, turbidez, amônia, alumínio, cobre, cloretos, ferro total, manganês, nitratos, nitritos, sulfatos e zinco por espectrofotometria.

As análises microbiológicas das águas superficiais não foram realizadas, tendo em vista que, essas águas, geralmente, apresentam contaminação natural, tornando-se impróprias para consumo humano, sem prévio tratamento. No entanto, as análises microbiológicas (coliformes totais e termotolerantes) do manancial

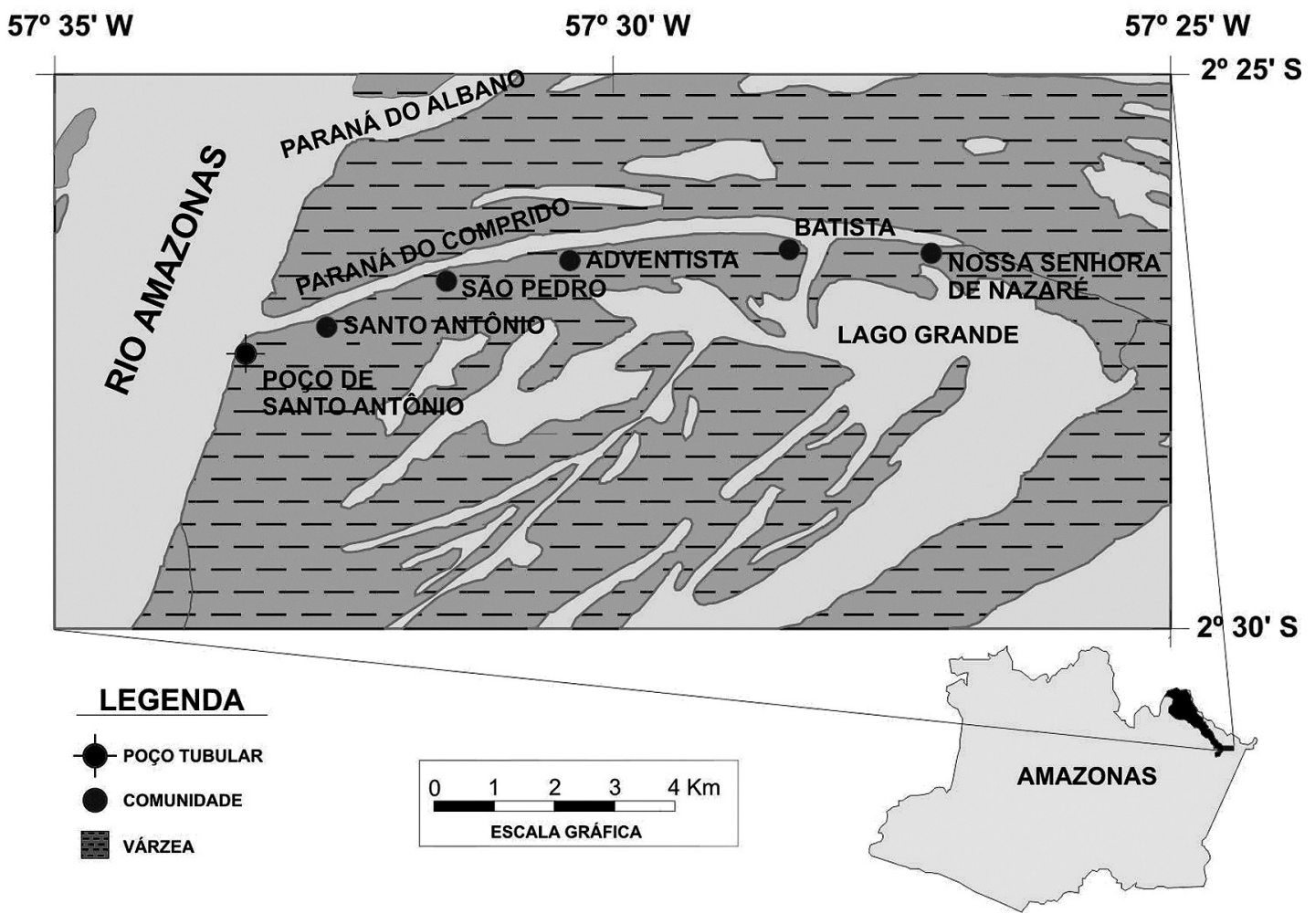

Figura 1 - Mapa de localização da área de estudo (comunidades do Paraná do Comprido e do poço tubular) 


\section{ACTA \\ AMAZONICA}

USO DE ÁGUA SUBTERRÂNEA EM SISTEMA DE ABASTECIMENTO

PÚBLICO DE COMUNIDADES NA VÁRZEA DA AMAZÔNIA CENTRAL

subterrâneo (poço tubular da comunidade), foram realizadas na sede do município de Urucará - AM, logo após a realização das coletas. Para tanto, foi utilizado um laboratório portátil específico para essa finalidade, sendo utilizado o método da membrana filtrante.

As metodologias utilizadas nas análises físico-químicas e microbiológicas foram as preconizadas no Standard Methods for the Examination of Water and Wastewater, publicação da American Public Health Association - APHA (1998).

Os dados coletados dos mananciais de superfícies e subterrâneos possibilitaram montar uma pequena série com as principais variáveis das águas analisadas e, foram comparadas com os Valores Máximos Permitidos (VMP) preconizados pela Portaria n. ${ }^{\circ}$ 518/2004 do Ministério da Saúde (BRASIL, 2004), que estabelece os procedimentos e responsabilidades relativos ao controle e vigilância da qualidade da água para consumo humano e seu padrão de potabilidade.

\section{LITOLOGIA LOCAL E CARACTERISTICAS CONSTRUTIVAS DO POÇO TUBULAR}

A litologia local inicialmente apresenta uma camada vegetal com espessura de 0,80 metro, seguida de argilas cinza-escuras com marcante presença de matéria orgânica até a profundidade de 26 metros. Na seqüência apresenta siltes e areia fina de cor cinza-escura até 80 metros de profundidade, onde encontra uma argila compacta com 2 metros de espessura. A partir dos 82 metros aparecem os aqüíferos, com ocorrência de areias de coloração amarela e branca, friáveis, heterogêneas de granulação média e de boa importância hidrogeológica, sendo intercaladas por argilas até 130 metros.

O poço tubular foi construído em 1999, atende a mais quatro comunidades vizinhas e suas principais características construtivas são:

- a profundidade da sondagem foi de 130 metros no diâmetro de 12 1/4";

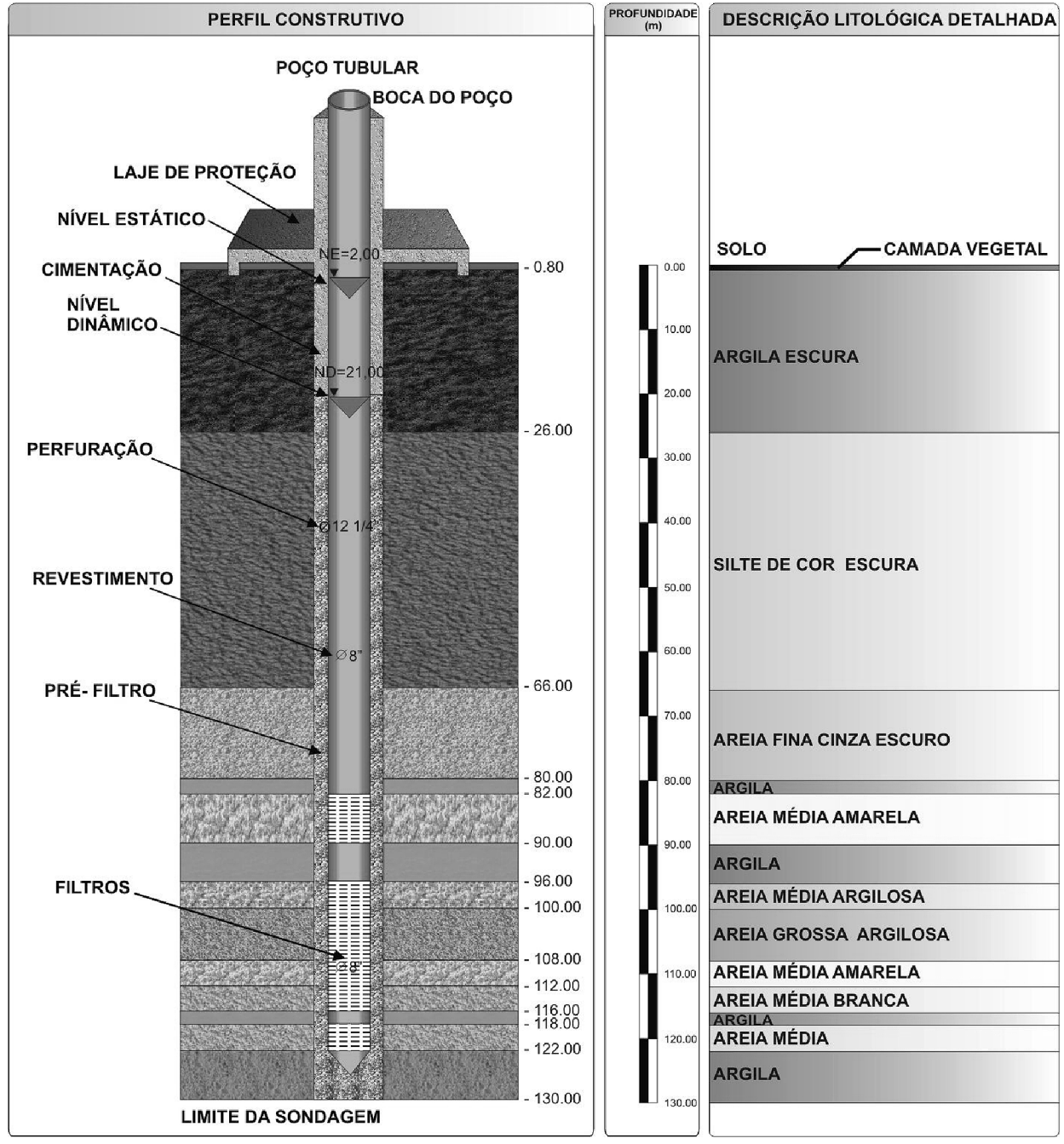

Figura 2 - Perfil construtivo do poço tubular da comunidade de Santo Antônio. Município de Urucará - AM. Brasil. 


\section{ACTA}

- no revestimento foram utilizados tubos de PVC (Polyvinyl chloride ou Policloreto de vinila) aditivado reforçado no diâmetro de 8". O filtro utilizado também foi de PVC aditivado no diâmetro de 8" e com abertura das ranhuras de $0,5 \mathrm{~mm}$. Os filtros permitem a passagem da água subterrânea para o poço e o posicionamento deles ocorreu nos intervalos de 82 a 90, de 96 a 116 e de 118 a 122 metros;

- como pré-filtro, foi utilizado seixo selecionado com granulometria de 3 a 5 mm e constituição mineralógica composta por $95 \%$ de material quartzoso de grãos de morfologia subarredondados a arredondados.

- a cimentação (previne riscos de contaminação ou mineralização isolando as camadas julgadas indesejadas para explotação de água subterrânea) não ultrapassou a 20 metros de profundidade;

- a laje de proteção sanitária foi construída no nível do terreno, com espessura $15 \mathrm{~cm}$ e área de $2,0 \mathrm{~m}^{2}$;

- a boca do poço ficou 1,7 metro acima do nível do terreno, ou seja, mais de 0,5 metro acima da cota de maior cheia ocorrida na localidade. Externamente foi revestida com concreto para resistir às tensões provocadas por banzeiro e por possíveis choques com troncos de árvores durante as cheias;

A figura 2 mostra o perfil construtivo do poço tubular e detalha a litologia local.

Sobre o poço foi construído um abrigo de proteção dos equipamentos elétricos, com laje de piso construída a 1,2 metro acima do nível do terreno. As figuras 3 e 4 mostram o poço na seca (vazante) e na cheia respectivamente;

\section{RESULTADOS E DISCUSSÃO}

\section{MANANCIAL DE SUPERFÍCIE: SEU APROVEITAMENTO PARA CONSUMO HUMANO}

$\mathrm{Na}$ área estudada, ocorrem diversos mananciais de superfície como paranás, igarapés, lagos, além do próprio rio Amazonas. O

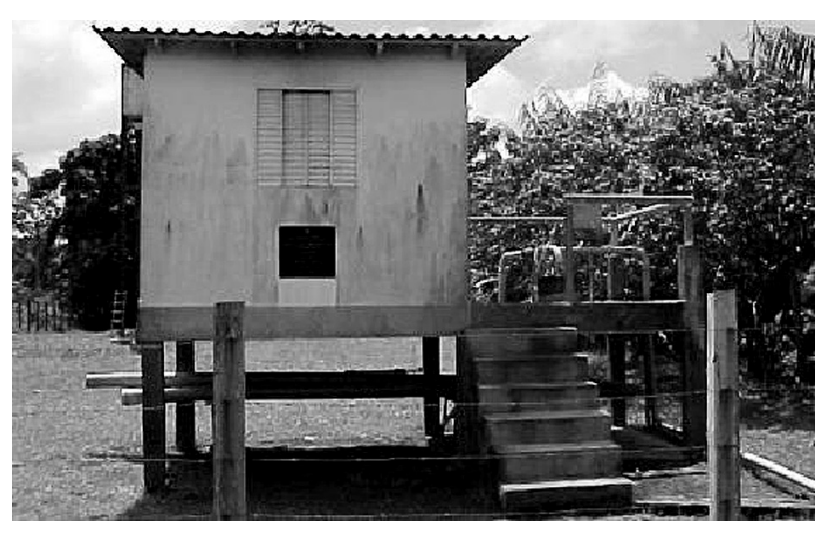

Figura 3 - Abrigo de proteção para equipamentos elétricos do poço tubular na vazante. Comunidade de Santo Antônio. Município de Urucará - AM. Brasil. aproveitamento do manancial de superfície como fonte de suprimento de água para abastecimento público na área de várzea é dificultado por pressões ambientais importantes como: elevada flutuação no nível das águas (superior a dez metros), surgimento de mosaicos formados por praias e bancos de areia, quedas de barrancos (fenômeno da terra caída), além da exigência do tratamento químico da água.

Segundo Richter \& Azevedo Netto (1991), a decisão mais importante para um projeto de abastecimento de água é a definição do manancial a ser utilizado como fonte de suprimento. Sempre que houver duas ou mais fontes possíveis, a sua seleção deve se apoiar em estudos amplos, que não se restrinjam exclusivamente a aspectos econômico-financeiros. A qualidade da água, as tendências futuras relativas à sua preservação e as condiçōes de segurança devem, também, ser pesadas.

A tabela 1 retrata as características físico-químicas das águas superficiais do rio Amazonas (principal manancial de superfície da comunidade) em dois períodos distintos (cheia máxima e seca ou vazante).

Comparando esses resultados com os estudos de caracterização hidroquímica do rio Amazonas na vazante, realizados por Santos \& Botelho (1988), em frente à cidade de Parintins - AM (distante $100 \mathrm{~km}$ jusante da área estudada), com água coletada no meio do rio a $30 \mathrm{~cm}$ de profundidade mostraram a cor com $51 \mathrm{mg} / \mathrm{Pt} / \mathrm{L}$, o pH 6,39, a condutividade $48,65 \mu$ S. $\mathrm{cm}^{-1}$, o cloro em forma de cloretos $1,7 \mathrm{mg} / \mathrm{L}$, o ferro total aparece com 1,82 $\mathrm{mg} / \mathrm{L}$ e o manganês $0,07 \mathrm{mg} / \mathrm{L}$.

Verifica-se que esses valores estão coerentes aos descritos na Tabela 1, exceto a cor aparente expressa em unidade de Hazen (mg/L Pt-Co) que apresentou um a grande discrepância nos dois períodos estudados. Em sistemas públicos de abastecimento de água, a cor é esteticamente indesejada para o consumidor, e pode ter origem mineral ou vegetal, causadas por substâncias metálicas como o ferro e o manganês (comuns nas águas do rio Amazonas), matérias húmicas, algas, plantas aquática e protozoários.

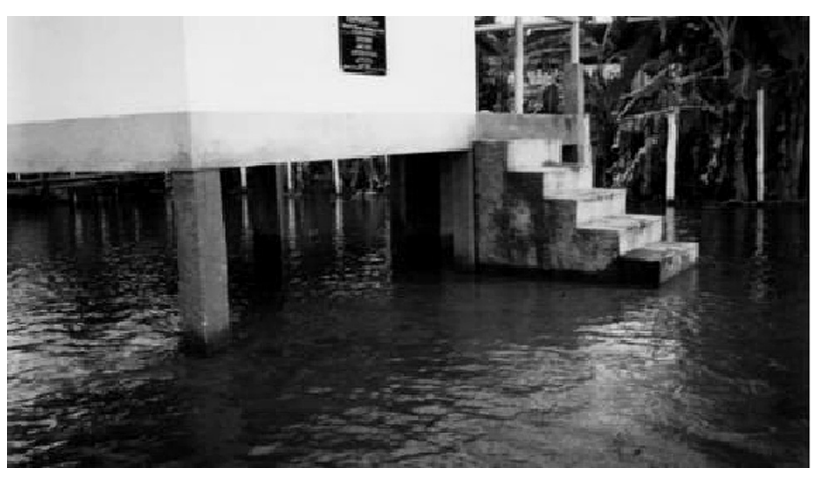

Figura 4 - Abrigo de proteção para equipamentos elétricos do poço tubular na cheia. Comunidade de Santo Antônio. Município de Urucará - AM. Brasil. 
Tabela 1 - Características das águas do rio Amazonas. Estado do Amazonas. Brasil.

\begin{tabular}{|c|c|c|c|c|}
\hline \multirow[b]{2}{*}{ Variável } & \multirow[b]{2}{*}{ Unidade } & \multirow[b]{2}{*}{ VMP } & \multicolumn{2}{|c|}{$\begin{array}{l}\text { Data da coleta e nível das águas do } \\
\text { rio Amazonas }\end{array}$} \\
\hline & & & $\begin{array}{c}\text { 24/06/2003 } \\
\text { (Cheia máxima) }\end{array}$ & $\begin{array}{c}20 / 11 / 2003 \\
\text { (Seca) }\end{array}$ \\
\hline Cor aparente & $\mathrm{uH}$ & 15 & 184 & 511 \\
\hline Turbidez & uT & 5 & 33 & 94 \\
\hline $\mathrm{pH}$ & - & 6 a 9,5 & 5,9 & 6,7 \\
\hline Condutividade & $\mu \mathrm{S} . \mathrm{cm}^{-1}$ & - & 50 & 66 \\
\hline Amônia & mg/L NH3 & 1,5 & 0,3 & 0,4 \\
\hline Dureza Total & $\mathrm{mg} / \mathrm{L} \mathrm{CaCO3}$ & 500 & 24 & 26 \\
\hline Alumínio & $\mathrm{mg} / \mathrm{L} \mathrm{Al}$ & 0,2 & 0,01 & 0,05 \\
\hline Cobre & $\mathrm{mg} / \mathrm{L} \mathrm{Cu}$ & 0,2 & 0,02 & 0,03 \\
\hline Cloretos & $\mathrm{mg} / \mathrm{L} \mathrm{Cl}$ & 250 & 4,0 & 2,5 \\
\hline Ferro Total & $\mathrm{mg} / \mathrm{L} \mathrm{Fe}$ & 0,3 & 1,81 & 2,3 \\
\hline Manganês & $\mathrm{mg} / \mathrm{L} \mathrm{Mn}$ & 0,1 & 0,06 & 0,09 \\
\hline Nitratos & $\mathrm{mg} / \mathrm{L} \mathrm{N}$ & 10 & nd $(<0,01)$ & 1 \\
\hline Nitritos & $\mathrm{mg} / \mathrm{L} \mathrm{N}$ & 1 & nd $(<0,001)$ & nd $(<0,001)$ \\
\hline Sulfato & $\mathrm{mg} / \mathrm{L} \mathrm{S04}$ & 250 & $\mathrm{nr}$ & $\mathrm{nr}$ \\
\hline Zinco & $\mathrm{mg} / \mathrm{L} \mathrm{Zn}$ & 5 & 0,12 & 0,3 \\
\hline
\end{tabular}

É possível que a coleta realizada na margem do rio também tenha contribuído com o resultado elevado da cor aparente, pois estudos realizados por Furch \& Junk (1997) no rio Solimões/ Amazonas, indicam haver uma grande diferença na característica físico-químicos da água, principalmente dos sólidos em suspensão que variam com a estação do ano, com a profundidade da coleta e com a distância ponto de coleta a margem.

A turbidez é atribuída principalmente às partículas sólidas em suspensão (muito comum nas águas dos rios de várzea), sendo que na localidade ocorre um processo natural de erosão conhecido com "fenômeno da terra caída". A turbidez foi expressa em unidade de Turbidez (Nefelométrica) e, sempre apresentou valores muito superiores aos valores máximos permissíveis pela Portaria n. ${ }^{\circ}$ 518/2004.

Na cheia máxima houve redução da condutividade elétrica e do $\mathrm{pH}$, segundo Junk (1983), a água do rio Amazonas mostra uma condutividade elétrica entre 60 a $70 \mu \mathrm{S} . \mathrm{cm}^{-1} / 20^{\circ} \mathrm{C}$, na várzea foram medidos valores entre 7 e acima de $700 \mu \mathrm{S} . \mathrm{cm}^{-1} / 20$ ${ }^{\circ} \mathrm{C}$. Do mesmo modo varia o $\mathrm{pH}$ entre 4,5 perto da terra firme até acima de 8 durante o desenvolvimento de algas em grande quantidade nos lagos de várzea.

Em relação aos metais, o ferro total apresentou nas duas análises valores superiores ao VMP da Portaria n. ${ }^{\circ}$ 518/2004, já o manganês, o alumínio, o cobre e o zinco ficaram com valores inferiores aos limites estipulados na citada Portaria

Os resultados das análises físico-químicas realizadas na água do rio Amazonas nesses dois períodos, confirmam que as mesmas são impróprias para o consumo humano em seu estado natural. Assim, por ocasião da escolha do manancial abastecedor da comunidade levou a desconsiderar-se o aproveitamento do manancial de superfície.

\section{QUALIDADE DA ÁGUA SUBTERRÂNEA}

A água subterrânea constitui-se uma importante fração dos recursos hídricos disponíveis. Apresenta normalmente em seu estado natural excelentes condiçôes para todo tipo de uso. A qualidade dessa água, no entanto, pode ser modificada direta ou indiretamente por atividades antrópicas, onde se inclui a construção de obras de captação inadequadas (poços tubulares).

A Tabela 2 mostra as principais características físico-químicas e microbiológicas da água do poço da comunidade de Santo Antônio em três períodos distintos do nível das águas superficiais.

Os resultados da série de análises físico-químicas da água contidos na Tabela 2 evidenciam baixas concentraçôes dos constituintes em solução. Estudos realizados por Tancredi (1996), na água subterrânea da região de Santarém - PA, na Formação Alter do Chão a mesma da área estudada, apontam que esses baixos teores resultam da natureza geológica dessa formação, constituída de sedimentos de composição quartizosa, através dos quais a água subterrânea circula, bem como, pela a elevada pluviosidade característica da região.

O nível estático do poço também sofre variaçōes ao longo do ciclo das águas superficiais e, na cheia máxima chega a ficar bem próximo do nível do terreno.

$\mathrm{O} \mathrm{pH}$ pouco variou, ficando dentro do limite estabelecido pela Portaria n. ${ }^{\circ}$ 518/2004, muito embora, próximo ao limite inferior.

Na cheia máxima, verificou-se que houve a elevação das concentraçôes do ferro total, que depois de oxidado contribuiu para a elevação da cor aparente. De acordo com estudos realizados pelo Projeto RADAMBRASIL (1976), na cheia, os solos de várzea são naturalmente saturados e os horizontes podem apresentar mosqueamentos em conseqüência do ferro livre sofrer alternadamente reduções e oxidações. O ferro trivalente, em condiçōes de hidromorfismo, é reduzido, dando coloração cinzaescura ao solo; quando cessa a saturação hídrica, permitindo a introdução de ar nas camadas do solo, toma o lugar a oxidação do ferro, principalmente as raízes, fendas e poros, onde a aeração é mais fácil.

Segundo Azevedo (2004), as altas concentraçôes dos teores de ferro no poço tubular da Comunidade de Santo Antônio no período de cheia, já ocorreram em anos anteriores, o resultado da análise da água coletada em 24/04/2000 detectou a concentração de $1,29 \mathrm{mg} / \mathrm{L}$ para o ferro total.

O ferro é objetável nos sistemas públicos de água, devido ao sabor que provoca e a sua propriedade de sujar os acessórios das tubulaçōes, provocar mancha na roupa lavada e acumular depósitos no sistema de distribuição. Segundo Batalha \& Parlatore 
Tabela 2 - Características da água do poço tubular da comunidade de Santo Antônio. Município de Urucará - AM. Brasil.

\begin{tabular}{|c|c|c|c|c|c|}
\hline \multirow[b]{2}{*}{ Variável } & \multirow[b]{2}{*}{ Unidade } & \multirow[b]{2}{*}{ VMP } & \multicolumn{3}{|c|}{ Data da coleta e nível das águas do rio Amazonas } \\
\hline & & & $\begin{array}{c}05 / 02 / 2003 \\
\text { (Enchente) }\end{array}$ & $\begin{array}{c}24 / 06 / 2003 \\
\text { (Cheia máxima) }\end{array}$ & $\begin{array}{c}20 / 11 / 2003 \\
\text { (Seca) }\end{array}$ \\
\hline Cor aparente & $\mathrm{UH}$ & 15 & 1 & 29 & 7 \\
\hline Turbidez & UT & 5 & nd $(<1)$ & 4 & 1 \\
\hline $\mathrm{pH}$ & - & 6 a 9,5 & 6,1 & 6,4 & 6,3 \\
\hline Condutividade & $\mu \mathrm{S} . \mathrm{cm}^{-1}$ & - & 75 & 123 & 70 \\
\hline Amônia & $\mathrm{mg} / \mathrm{L} \mathrm{NH3}$ & 1,5 & $\mathrm{nd}(<0,01)$ & 0,01 & nd $(<0,01)$ \\
\hline Dureza Total & $\mathrm{mg} / \mathrm{L} \mathrm{CaCO3}$ & 500 & 15 & 34 & 13 \\
\hline Alumínio & $\mathrm{mg} / \mathrm{L} \mathrm{Al}$ & 0,2 & $\mathrm{nd}(<0,01)$ & $\mathrm{nd}(<0,01)$ & 0,01 \\
\hline Cobre & $\mathrm{mg} / \mathrm{L} \mathrm{Cu}$ & 0,2 & 0,07 & 0,07 & 0,01 \\
\hline Cloretos & $\mathrm{mg} / \mathrm{L} \mathrm{Cl}$ & 250 & 1,1 & 4,1 & $\mathrm{nd}(<1)$ \\
\hline Ferro Total & $\mathrm{mg} / \mathrm{L} \mathrm{Fe}$ & 0,3 & 0,16 & 0,92 & 0,2 \\
\hline Manganês & $\mathrm{mg} / \mathrm{L} \mathrm{Mn}$ & 0,1 & 0,004 & 0,016 & 0,02 \\
\hline Nitratos & $\mathrm{mg} / \mathrm{L} \mathrm{N}$ & 10 & 0,1 & 0,09 & 0,3 \\
\hline Nitritos & $\mathrm{mg} / \mathrm{L} \mathrm{N}$ & 1 & 0,005 & 0,004 & 0,004 \\
\hline Sulfato & $\mathrm{mg} / \mathrm{L} \mathrm{S04}$ & 250 & nd $(<1)$ & $\mathrm{nr}$ & 1 \\
\hline Zinco & $\mathrm{mg} / \mathrm{L} \mathrm{Zn}$ & 5 & 0,2 & 0,14 & 0,13 \\
\hline Coliforme total & Ausência/100ml & Ausência & Ausente & $\mathrm{nr}$ & Ausente \\
\hline Coliforme termotolerante & Ausência/100ml & Ausência & Ausente & $\mathrm{nr}$ & Ausente \\
\hline
\end{tabular}

VMP = Valor Máximo Permissivel pela Portaria n. ${ }^{0}$ 518/2004. nd = Parâmetro com valor abaixo do limite de detecção do método. nr = Parâmetro não realizado

(1977), a necessidade de se fixar um padrão prende-se muito mais a razôes estéticas do que propriamente por ordem sanitária, uma vez que a quantidade nutricional do ferro no homem é da ordem de 1 a $2 \mathrm{mg} /$ dia, sempre que a absorção seja normal. Num sistema de abastecimento de água, concentrações de ferro menor que $0,3 \mathrm{mg} / \mathrm{L}$ são geralmente aceitáveis.

O mais provável é que a ocorrência de ferro no poço na época da cheia máxima seja devido a problemas construtivos, principalmente pelo não isolamento correto das camadas litológicas indesejáveis. O recomendável seria proceder a cimentação até a profundidade de 82 metros para isolar essas camadas, no entanto, dificuldades encontradas na realização desse procedimento durante a construção do poço, indicam que a cimentação não ultrapassou a 20 metros de profundidade, possibilitando com que águas das camadas indesejadas e não isoladas cheguem aos lençóis mais profundos.

Os melhores aqüíferos estão localizados em profundidades superiores a 82 metros. De acordo com Azevedo (2004), profundidades menores para poços na área estudada já foram tentadas sem sucesso.

Não foram detectadas presenças coliformes (totais e termotelarantes). A possibilidade de contaminação por esses microorganismos seria através da infiltração no poço de águas superficiais ou do lençol freático - mais sujeitos a essa contaminação. Isso é um indicativo que a laje de proteção sanitária e a cimentação reduzem a possibilidade de contaminação por coliformes. Além disso, o primeiro filtro está posicionado a 82 metros de profundidade minimizando ainda mais a contaminação por esses microorganismos.

O aproveitamento do lençol subterrâneo por meio de poço tubular não depende exclusivamente dos aquíferos, depende e muito da tecnologia construtiva utilizada, uma vez que as possibilidades de armazenamento e condução de água nesses aquíferos são determinadas por propriedades físicas como a porosidade, permeabilidade, seleção e arranjo dos grãos, cimentação e composição mineral.

A água subterrânea da regiāo de várzea de Urucará - AM, na Amazônia Central, apresenta em seu estado natural, boas condiçôes de potabilidade. No entanto, o processo construtivo deficiente do poço tubular, pode comprometer esses aqüíferos tornando-os mais vulneráveis a contaminação devido às próprias obras de captação.

O processo de concepção e construção de poços tubulares em área de várzea na Amazônia não é definitivo, muito pelo contrário, ainda está apenas nos seus primórdios, onde os insucessos de alguns poços nessas áreas, de alguma maneira, estão contribuindo para o aprimoramento e consolidação do avanço do conhecimento científico sobre o assunto.

\section{CONCLUSÕES E RECOMENDAÇ̃̃ES}

As águas superficiais de várzea da comunidade estudada, não são apropriadas para consumo humano sem tratamento adequado. 
O manancial subterrâneo local apresenta condições hidrogeológicas satisfatórias para seu aproveitamento em um sistema público de abastecimento de água.

O poço tubular da comunidade apresentou falhas no processo construtivo, principalmente na cimentação, que tem por finalidade isolar as camadas indesejáveis, indicando que o poço não está completamente isento de receber água de lençóis indesejados.

No período pesquisado as características físico-químicas e microbiológicas da água subterrânea local explotada do poço tubular demonstraram ser potáveis ao longo de um ciclo das águas superficiais, exceto no período de cheia máxima onde a cor aparente e o ferro total apresentaram as maiores alteraçóes.

O ferro total foi o parâmetro que mais aumentou, ultrapassando em mais de três vezes o valor máximo permissível pela Portaria n. ${ }^{\circ}$ 518/2004. No entanto, a depender da concentração do ferro total, o mesmo pode ser significativamente reduzido com uma simples aeração da água.

Pouca importância se tem dado à perfuração dos poços em comunidades rurais da Amazônia onde se inclui, também, as comunidades de várzea. Nota-se que são raríssimos os poços construídos dentro das técnicas adequadas, com coletas e ensaios de materiais, onde seja feita a caracterização fiel da sondagem realizada. A falta desses elementos traz como conseqüência um quase total desconhecimento dos aspectos construtivos do poço, bem como a litologia do local, podendo comprometer a qualidade da água a ser distribuída à população ribeirinha.

O estudo demonstrou que a utilização do lençol subterrâneo através de poço tubular profundo, para abastecimento público de água nas comunidades de várzea na Amazônia é tecnicamente viável. No entanto, requer obras de captação corretas, visando a conservação da qualidade da água subterrânea nesse rico ecossistema sujeito a inundaçōes periódicas.

Mais pesquisas são necessárias sobre a utilização da água subterrânea na várzea Amazônica, cabendo as nossas autoridades despertarem para o tema.

\section{BIBLIOGRAFIA CITADA}

APHA. American Public Health Association. 1998. Standard Methods for the Examination of Water and Wastewater. $20 \mathrm{ed}$. Washington: APHA-AWWA-WEF. 1220pp.

Azevedo Netto, J. M.; Alvarez, G. A. 1991. Manual de Hidráulica. 7. ed. São Paulo: Edgard Blücher, v. II. p. 333-724.
Azevedo, R. P. 2004. Sistema de Abastecimento de Água em Comunidades Rurais de Várzea na Amazônia: da utopia da implantação ao desafio da gestão sustentável. Dissertação de Mestrado Universidade Federal do Amazonas, Manaus, Amazonas. 160pp.

Batalha, B. L.; Parlatore, A. C. 1977. Controle da qualidade da água para consumo humano: bases conceituais e operacionais. São Paulo: CETESB, 198pp.

BRASIL. Portaria n. ${ }^{\circ}$ 518, de 25/03/2004 do Ministério da Saúde. Estabelece os procedimentos e responsabilidades relativos ao controle e vigilância da qualidade da água para consumo humano e seu padrão de potabilidade. In: Diário Oficial da Uniāo, Brasília, n. 59, Seção 1, p. 266, 26/03/2004.

CETESB. Companhia de Tecnologia de Saneamento Ambiental. 1987. Guia de coleta e preservação de amostras de água. São Paulo: CETESB, 150pp.

Diegues, A. C. (Org.) 2002. Povos e águas: inventário de áreas úmidas. 2. ed. São Paulo: NUPAUB-USP, 597pp.

Furch, K.; Junk, W. J. 1997. Physicochemical conditions in the floodplains. Ecological Studies, 126: 69-108.

Junk, W. J. 1983. As águas da região Amazônica. In: SALATI, Eneas et al. Amazônia: desenvolvimento, integração e ecologia. São Paulo: Brasiliense, p. 54-55.

Martineli, L. A. 1986. Composição química e isotópica $\left({ }^{13} \mathrm{C}\right)$ de sedimentos de várzea e suas interaçôes com alguns rios da bacia Amazônica. Dissertação de Mestrado Universidade de São Paulo, Piracicaba, São Paulo, 214pp.

Petri, S.; Fúlfaro, V. J. 1983. Geologia do Brasil. São Paulo: EDUSP,. 631pp.

PROJETO RADAMBRASIL. 1976. Folha SA-21-Santarém: geologia, geomorfologia, pedologia, vegetação e uso potencial da terra (Levantamento de Recursos Naturais). Rio de janeiro, v. $10.522 \mathrm{pp}$.

Richter, C. A.; Azevedo Netto , J. M. 1991. Tratamento de água: tecnologia atualizada. São Paulo: Edgard Blücher, 332pp.

Santos, U. M.; Ribeiro, M. N. G. 1988. A hidroquímica do rio Solimões - Amazonas. Acta Amazônica, 18 (3/4): 145-173.

Tancredi, A. C. F. N. S. 1996. Recursos hidricos subterrâneos de Santarém: fundamentos para uso e proteção. Tese de Doutorado Universidade Federal do Pará, Belém, Pará, 146pp.

Urban, T. (Coord.). 1999. Manual para elaboração de plano de manejo e gestāo de bacia de manancial. 2. ed. Curitiba: SANEPAR, 184pp.

Recebido em 17/01/2005

Aceito em 22/05/2006 